\title{
Agulhas ring injection into the South Atlantic during glacials and interglacials
}

\author{
V. Zharkov $^{1}$ and D. Nof ${ }^{1,2}$ \\ ${ }^{1}$ Geophysical Fluid Dynamics institute, Florida State University, USA \\ ${ }^{2}$ Department of Oceanography, Florida State University, USA
}

Received: 22 November 2007 - Published in Ocean Sci. Discuss.: 17 March 2008

Revised: 23 July 2008 - Accepted: 27 August 2008 - Published: 30 September 2008

\begin{abstract}
Recent proxies suggest that, at the end of the last glacial, there was a significant increase in the injection of Agulhas rings into the South Atlantic (SA). This brought about a dramatic increase in the salt-influx (from the Indian Ocean) into the SA helping re-start the then-collapsed meridional overturning cell (MOC), leading to the termination of the Younger Dryas (YD). Here, we propose a mechanism through which large variations in ring production take place.

Using nonlinear analytical solutions for eddy shedding, we show that there are restricted possibilities for ring detachment when the coast is oriented in the north-south direction. We define a critical coastline angle below which there is rings shedding and above which there is almost no shedding. In the case of the Agulhas region, the particular shape of the African continent implies that rings can be produced only when the retroflection occurs beyond a specific latitude where the angle is critical. During glaciation, the wind stress curl (WSC) vanished at a latitude lower than that of the critical angle, which prohibited the retroflection from producing rings. When the latitude at which the WSC vanishes migrated poleward towards its present day position, the corresponding coastline angle decreased below the critical angle and allowed for a vigorous production of rings.

Simple process-oriented numerical simulations (using the Bleck and Boudra model) are in satisfactory agreement with our results and enable us to affirm that, during the glacials, the behavior of the Agulhas Current (AC) was similar to that of the modern East Australian Current (EAC), for which the coastline slant is supercritical.
\end{abstract}

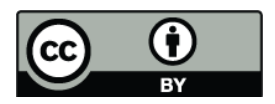

Correspondence to: D. Nof (nof@ocean.fsu.edu)

\section{Introduction}

In a recent article (Zharkov and Nof, 2007; ZN, hereafter) we examined the development of a nonlinear retroflection and constructed a solution describing the time-evolution of the ring and the mass flux going into it. Here, we shall consider the later stages in the eddies' evolution - their detachment and propagation away from their generation area. We will focus on the angle of the coastline slant, supposing the incoming current to be parallel to it, and show that, when this angle exceeds a critical value, the frequency of eddy detachment is severely restricted. We shall see that this may explain why very few Agulhas eddies were injected into the Atlantic during the Last Glaciation maximum (LGM) and the Younger Dryas (YD).

\subsection{Observational background}

Agulhas Current (AC) rings transport water from the Indian Ocean to the South Atlantic (SA) and, therefore, contribute to the near-surface return flow of the North Atlantic Deep Water (NADW) from the Pacific and Indian Oceans to the North Atlantic. The rings common transport represents a significant part of the meridional overturning circulation (MOC) (Gordon et al., 1987; Weijer et al., 1999; van Aken, 2003; Lutjeharms, 2006) but their most important component comes from their anomalous salt content which brings in a salt anomaly five times as large as that of the Mediterranean outflow. The shedding of Agulhas rings is not a regular event. Some rings immediately split after formation, while others are recaptured by the retroflection. Furthermore, although the typical frequency of shedding is 4-5 times a year (Schouten et al., 2002), intervals of over half-a-year without a ring-shedding event have been observed (Goni et al., 1997).

Recent paleoceanographic proxies analysis (Rau et al., 2002; Peeters et al., 2004), suggest that the Indian-Atlantic

Published by Copernicus Publications on behalf of the European Geosciences Union. 
water exchange has varied greatly throughout the past 550000 years, having been enhanced during interglacials, and strongly reduced during glacial intervals. One can tentatively suggest, on the basis of Howard and Prell (1992), and Berger and Wefer (1996), that the glacial Agulhas leakage was completely shutoff due to a northward migration of the wind bands. It is important to realize that, strictly speaking, this explanation is incorrect, as the wind field controls the ocean interior but not the $\mathrm{AC}$, i.e. rings can still propagate along the coast and penetrate into the Atlantic even when the western boundary current (WSC) vanishes north of the continental southern termination.

We note below that, even a limited reduction in ring influx, could explain why the glacial Atlantic MOC could easily collapse. Given a smaller input from Agulhas rings, the salt content of the Atlantic reduced and decreased the strength of the MOC. Because an increase in ring activity brings more salt to the Atlantic Ocean (Knorr and Lohmann, 2003), the suggestion of Peeters et al. (2004) that there was vigorous Agulhas ring activity at the end of each glacial might explain how a collapsed MOC restarted. The onset of increasing Agulhas leakage during late glacial conditions took place when glacial ice volume was maximal, and this suggests the crucial role of Agulhas leakage in glacial terminations, timing of inter-hemispheric climate change, and the resulting resumption of the Atlantic MOC. The question that we address here is: Why were there more rings during the end of the glacial?

\subsection{Salt balance}

The importance of the Agulhas rings salt-flux to the MOC was already established by Weijer et al. (2001) and Speich et al. (2006) but it is useful to re-capture here the main aspects of the issue. The annualized volume transport associated with a typical Agulhas ring is estimated to be between 0.4 and 3.0 Sv (see e.g. de Ruijter et al., 1999). It is not a trivial matter to estimate the salt anomaly introduced by the rings. Many conventional calculations of the contributed anomaly are based on the salt difference between each ring and its immediate environment in the Southeastern Atlantic (SEA). This grossly underestimates the true contributed anomaly because the volume flux of the rings and their associated filaments (normally not counted as part of the rings), is so large ( $Q_{R}$ which is, say, $10 \mathrm{~Sv}$ ) that the whole SEA is full of relatively salty water from old rings.

To correctly do the estimate, one needs to consider the salinity that the SEA would have had in the absence of the rings. If one takes the SEA salinity $(S)$ in the absence of Agulhas rings to be slightly higher than the AAIW (Antarctic Intermediate Water) salinity (say, 34.5 PSU) and the rings salinity to be one PSU higher, 35.5 PSU, then the salinity anomaly $\left(Q_{R} \Delta S\right)$ contributed by the rings is roughly $10 \mathrm{~Sv}$ PSU. This is about five times the buoyancy anomaly contributed by the Mediterranean Sea or the Bering Strait.
Taking the MOC transport to be, say, $15 \mathrm{~Sv}$, and applying a simple interpolation, we find that a hypothetical removal of the entire Agulhas rings influx today (10 Sv of water 1 PSU saltier) would lower the MOC salinity by 0.7 PSU. About half of this quantity would be sufficient to collapse the MOC altogether under present day conditions (see Nof and Van Gorder, 2003, their Fig. 2, as well as Sandal and Nof, 2008) so a simple linearization suggests that the MOC transport would be reduced by $50 \%$.

\subsection{The glacial-interglacial hypothesis}

Under basic Sverdrup dynamics, when the basin is closed, its net meridional Sverdrup flow is compensated for by a WBC flowing in the opposite direction. The meridional component of the Sverdrup transport vanishes at the latitudes where the WSC vanishes $\left(\partial \tau_{x} / \partial y=0\right)$. This implies that the flow at these latitudes is purely zonal, so that, for a closed basin, the vanishing of the WSC also defines the location of the WBC separation. (Here, we use the term "separation" to describe the position of the detached current several deformation radii away from the coast. The term "retroflection" is used to describe a separation from a coastline whose slant is such that the current is turning upon itself when it detaches.)

Most ocean basins are not closed. The Indian Ocean is wide open, so significant WBC-induced meridional leakages can occur across the latitude of the vanishing WSC. We also note that, since the vanishing curl is approximately at the same latitude all around the globe, northward leakages must be compensated for by southward flow within boundary currents. In the Agulhas region, the position of zero WSC is roughly at the Subtropical Convergence Zone about $45^{\circ} \mathrm{S}$ (de Ruijter, 1982), which is beyond the termination of the continent. In view of these, we shall take the position of vanishing WSC to be the retroflection latitude but keep in mind that there can be leakages across it near the boundary. Furthermore, we will assume that the shift in the position of retroflection roughly follows the shift in the WSC (Fig. 1).

The above is easier said than done, because it is difficult to determine the exact latitude of the zero WSC in the Western Indian Ocean during the LGM and the YD. On one hand, it could be inferred from Peeters et al. (2004) that the Subtropical Convergence Zone was 2-5 degrees farther north during the YD. On the other hand, Gasse (2000) and Esper et al. (2004) argue that the shift of the westerly wind belt was much larger, up to at least $25^{\circ} \mathrm{S}$. This is supported by the analysis of proxies from the Pacific, where the shifting process was determined via the position of the (somewhat weaker) EAC. Note that, although the EAC is weaker than the AC, it is the Pacific analog of the AC. According to Martinez (1994), Kawagata (2001), Martinez et al. (2002), and Bostock et al. (2006), there was a large northward shift of the Tasman Front (a branch of the EAC) from its present latitude of $33^{\circ} \mathrm{S}$ to about $25^{\circ} \mathrm{S}$ during the last glacial. Tilburg et al. (2001) suggested that the WSC is not exactly zero at 
the latitude of the EAC separation, implying that the EAC does not separate completely from the coast. However, the WSC is minimal, and its gradient is maximal at the latitude of the formation of the Tasman Front, implying that the glacial/interglacial shifts of the EAC separation occurred mainly due to the shifts of the WSC.

In view of these aspects, we shall suppose that the Agulhas retroflection latitude, during both the LGM and the YD, was somewhere between $25^{\circ} \mathrm{S}$ and $31^{\circ} \mathrm{S}$ (instead of its present position of about $38^{\circ} \mathrm{S}$ ). We shall show that, with such a shift, the coastline slant in the neighborhood of the retroflection during the glacials (between 50 degrees and 70 degrees) severely restricted the formation of eddies. This is because the rings' long-wall drift speed was so small that they were not removed quickly enough from their formation region to avoid being re-captured. We shall see that this slower longwall migration rate (in case of a nearly meridional coastline) is due to the obvious blocking imposed by the wall.

We note here in passing that the slant of the Australian coastline at the point of the present day EAC separation is about 65 degrees, roughly the same as that of the glacial AC. This explains why EAC rings are not usually found around the southern tip of Tasmania - the coastline slant is just too high to allow rings shedding. As in the Agulhas case, anticyclonic eddies are detached from the EAC by the pinching-off of poleward meanders. However, in contrast to the present day Agulhas case, the eddies often coalesce with the EAC again (Nilsson et al., 1977; Andrews and Scully-Power, 1976; Nilsson and Cresswell, 1981; Sokolov and Rintoul, 2000).

The important aspect here is that none of the EAC rings (which, without the slanting coastline idea, would be the analogs of present day Agulhas rings in the SEA) is found west of Tasmania.

\subsection{Present approach}

We shall begin our study by examining the condition of ring shedding due to $\beta$. We will look at the theoretical ranges of detached eddies radii, their propagation speeds, and their periods of detachment, as well as the average amount of mass flux going into the rings. To examine our glacial-interglacial hypothesis regarding the critical slant angle, we shall analyze the dependence of the above-mentioned aspects on the slant angle and other model parameters. We will also present the results obtained from numerical simulations (using a "reduced gravity" model of the Black and Boudra type), which visually elucidate two different regimes of eddy generation.

The paper is organized as follows. Section 2 is devoted to the definitions of the lower and upper boundaries of the ring dimensions, position and drift speed. In Sect. 3, we analyze the results of our analytical modeling, and examine the critical angles of the slant. In Sect. 4, we give the results of our numerical simulations for sub-critical and supercritical slant angles, and compare them with our analytical calculations.

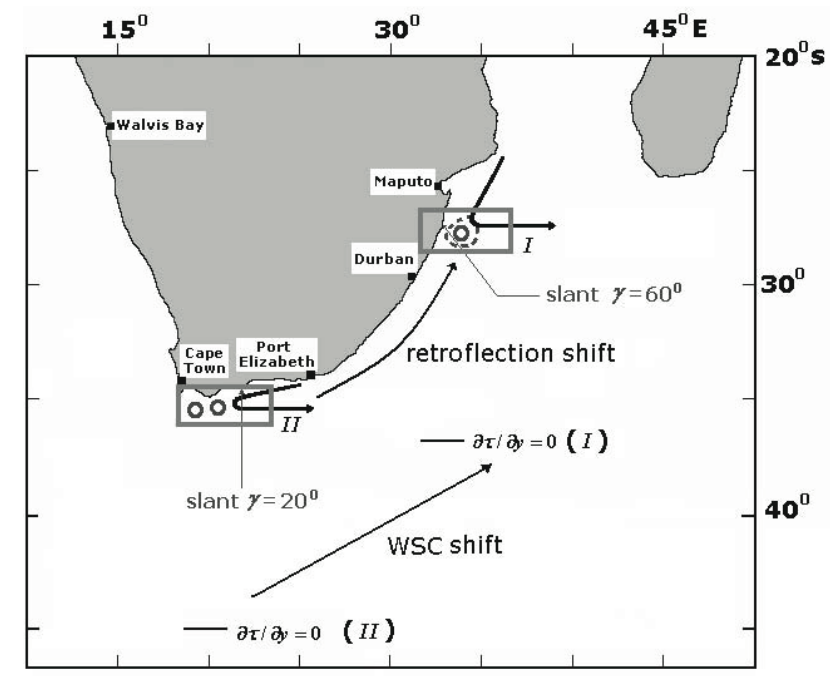

Fig. 1. Schematic diagram of the Agulhas retroflection and the detached rings. Note that the slant of the coastline relative to the meridional direction varies dramatically as one moves northward along the coast. The retroflection shift is a consequence of the WSC shift. Box I displays glacial conditions: the retroflection occurred at the lower latitudes where the coastal slant is about $60^{\circ}$. Ring shedding was rare because the translation velocity of the detached rings along the wall was small. Some rings could be dissipated or reabsorbed by the meandering current. Box II displays post-glacial conditions: the retroflection occurs at higher latitudes where the coastal slant is about $20^{\circ}$. A chain of rings is regularly shed because the migration speed along the wall is high.

Finally, in Sect. 5, we summarize the results and give the conclusions regarding the glacial-interglacial hypothesis.

\section{Shedding}

2.1 Governing equations and the long-wall eddy propagation rate

We begin with the nonlinear momentum-flux and mass conservation equations for the retroflection eddy [also referred to as the "basic eddy" (BE)] growth as given in ZN. The most relevant equations are (their) Eqs. (30) and (32), which are useful but cumbersome and, therefore, are not reproduced here. All the following formulae and computations are based on solutions of these equations for,

$R=R(t), \quad \Phi=\Phi(t), \quad H=H(t) \quad$.

Here, $R$ is the radius of developing eddy, $\Phi$ the ratio of the mass-flux going to the BE and the total incoming mass-flux $Q$, and $H$ is the thickness of the upper (moving) layer outside the retroflection area. All depend on $Q$ (incoming mass flux), $h_{0}$ (thickness of the upstream upper layer along the coast), $g^{\prime}$ (reduced gravity), $f_{0}$ (mean and absolute value of Coriolis parameter), $\alpha$ (twice Rossby number), $\beta$ (meridional 

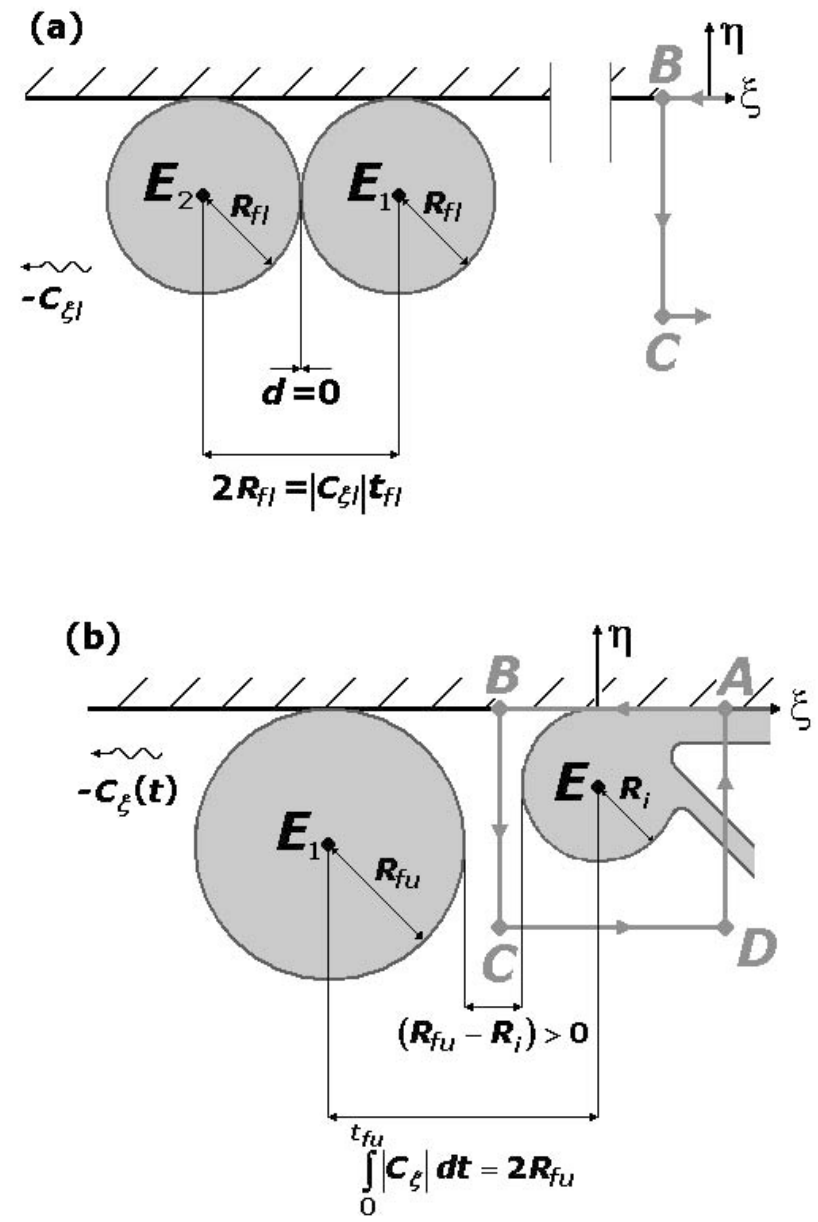

Fig. 2. Geometries associated with the lower and upper boundaries of the final eddy radius. The upper panel (a) shows two consecutive osculating eddies $(d=0)$ away from the retroflection. The detachment period $t_{f l}$ is obtained by a division of the doubled-final-eddyradius, $2 R_{f l}$, by the modulus of the final eddy migration rate. The segment BC corresponds to the western boundary of the integration area (see $\mathrm{ZN}$ ). The lower panel (b) shows the already detached eddy (centered in $E_{1}$ ) migrating at the rate $-C_{\xi}(t)$, and an incipient basic eddy (BE) centered in $E$. At the moment $t_{f u}$, the distance between the two eddies is $\left(R_{f u}-R_{i}\right)$, which is positive because the incipient $\mathrm{BE}$ is less developed. Therefore, our ABCD contour encloses only the incipient BE.

gradient of Coriolis parameter) and $\gamma$ (slant of the coast). We again use the tilted coordinate system $(\xi, \eta)$ adopted by $\mathrm{ZN}$. (For convenience, all variables are defined both in the text and the Appendix.)

Following Nof (2005), we consider ring shedding due to $\beta$ which, in the open ocean, forces the eddies westward (Nof, 1983) according to,

$C_{x} \approx-\beta\left[\frac{\alpha R^{2}}{12}+\frac{2 g^{\prime} H}{(2-\alpha) f_{0}^{2}}\right]$.
We then suppose that, in the case of a non-zonal wall, this velocity component along the wall is simply reduced due to the geometrical blocking of the wall,

$C_{\xi}=C_{x} \cos \gamma$.

The above is not a rigorous derivation of the long-wall drift speed but it will later be confirmed with our numerical simulations. We also note that this assumption is supported by the numerical calculations of Arruda et al. (2004), which demonstrated that no eddy detachment occurs in the case of a meridional wall $\left(\gamma=90^{\circ}\right)$. The so-called image-effect is neglected here on the ground that there is no image-effect in the limit $H \rightarrow 0$ (Shi and Nof, 1994) and $H$ is not very large (relative to the maximum eddy thickness) in most of our analysis. Our numerical simulation will later support this assumption even for $H$ that is not small, probably because the rings are formed off the wall.

2.2 Lower and upper boundaries for the radii of eddies and periods of their detachment

On the basis of the downstream eddies position (Fig. 2a), the generation period for each individual eddy is taken as,

$t_{f}=\left(2 R_{f}+d\right) /\left|C_{\xi f}\right|$,

where $d$ is the distance between two consecutive eddies, and the subscript $f$ denotes the final value. The "lower boundary" for the final eddy size $\left(R_{f l}\right)$ can be obtained using the "kissing condition" (i.e. $d=0$, Fig. 2a). In that case, Eqs. (24) give,

$t_{f l}=\frac{24(2-\alpha) f_{0}^{2} R_{f l}}{\beta\left[\alpha(2-\alpha) f_{0}^{2} R_{f l}^{2}+24 g^{\prime} H_{f l}\right] \cos \gamma}$.

Equation (5) implies that $R_{f l}=R\left(t_{f l}\right)$ and $H_{f l}=H\left(t_{f l}\right)$ and will be solved numerically.

Next, we derive the intricate "upper boundary" $\left(R_{f u}\right)$ for the final BE size (i.e. the detachment size). For this purpose, consider the configuration shown in Fig. 2b. During the generation period, the eddy is moving along the axis $\xi$ with the velocity $C_{\xi}$, which is a function of time and is defined by Eqs. (2-3). The displacement of the BE from its initial position during the generation period is $\int_{0}^{t_{f}}\left|C_{\xi}\right| d t$. We note that, when this displacement equals the final diameter of the eddy (i.e. $2 R_{f}$ ), then it must be detached because, at this point in time, it osculates the already generated eddy downstream (whose radius must also be $R_{f}$ ).

Since the distance between the centers of the two consecutive eddies may exceed the sum of their radii, we can place the segment of the integration contour surrounding the area of the BE between the two eddies (Fig. 2b), indicating that the formation of the second eddy is now in progress as the first one has already been fully developed and shed. In view 
of this, we write the condition of "upper boundary" in the form,

$$
\int_{0}^{t_{f u}}\left|C_{\xi}\right| d t=2 R_{f u},
$$

which is an (integral-algebraic) equation for $R_{f u}$.

Physically, the "upper boundary" corresponds more directly to the detachment of eddies, whereas the "lower boundary" corresponds to a condition for the formation of an eddy chain. Consequently, the eddies can detach and propagate out of the retroflection area if the condition,

$R_{f l} \leq R_{f u}$

is satisfied. This condition is certainly valid for the "imbalance paradox" (Nof, 2005), for which it is easy to show that when $R_{f l}$ significantly exceeds $R_{i}$ (the initial radius, see $\mathrm{ZN})$, then $R_{f u}=2^{1 / 5} R_{f l}$. For the upper boundary case $\left(R_{f}=R_{f u}\right)$, one obtains $d=d_{u}=2 R_{f u}$, implying that the distance between two consecutive eddies centers cannot exceed the eddy diameter.

\section{Analysis}

\subsection{Lower and upper boundaries and the critical angle}

We solved numerically the equations corresponding to Eqs. (5) and (6) using Eqs. (30) and (32) of $\mathrm{ZN}$. For this purpose, we used: $Q=70 \mathrm{~Sv}, g^{\prime}=2 \times 10^{-2} \mathrm{~ms}^{-2}$ and $f_{0}=8.8 \times 10^{-5} \mathrm{~s}^{-1}$ (corresponding to $35^{\circ}$ of latitude). We took zero and $300 \mathrm{~m}$ for $h_{0}$, and $2.3 \times 10^{-11}$ and $6 \times 10^{-11} \mathrm{~m}^{-1} \mathrm{~s}^{-1}$ for $\beta$. Alpha $(\alpha)$ and $\gamma$ varied between 0.1 and 1.0 , and between zero degrees and $89^{\circ}$, respectively. The results for $R_{f l}$ and $R_{f u}$ as functions of $\gamma$ are shown in Fig. 3. We see that the radii decrease with growing $\gamma$; for $\alpha=1$, this decrease is very week and non-monotonic. The curves depicting lower and upper boundaries gradually approach each other and intersect, finally converging. This intersection occurs when $\gamma$ exceeds $33^{\circ}$ for $\alpha \geq 0.5$, and $24^{\circ}$ for $\alpha \approx 0.2$. We consider the angles of intersection as critical values of $\gamma$.

When $\alpha$ is small, the curves converge very quickly and are then cut off where there is no solution. That occurs because, in this case when $\gamma$ is not very small, the $\beta$-force overwhelms the momentum flux of the currents so the BE is forced into the wall (instead of growing). For these particular conditions, $R_{f l}$, and $R_{f u}$ cannot be easily defined. To clarify this, we plotted $R_{i}, R_{f l}$, and $R_{f u}$ versus $\alpha$ (starting from $\alpha=0.1$ ) for different values of $\gamma$ (Fig. 3b). We see that the curves of $R_{f l}$ and $R_{f u}$ are defined for $\alpha=0.1$ only when $\gamma \leq 30^{\circ}$.

Figure 4 shows the periods of detachment $t_{f l}$ and $t_{f u}$ (Fig. 4a) and the velocities $C_{\xi l}$ and $C_{\xi u}$ of the detached eddies whose radii are $R_{f l}$ and $R_{f u}$ (Fig. 4b). Overall, the detachment period decreases with growing $\alpha$; however, it increases with increasing $\gamma$, tending to infinity for the case of
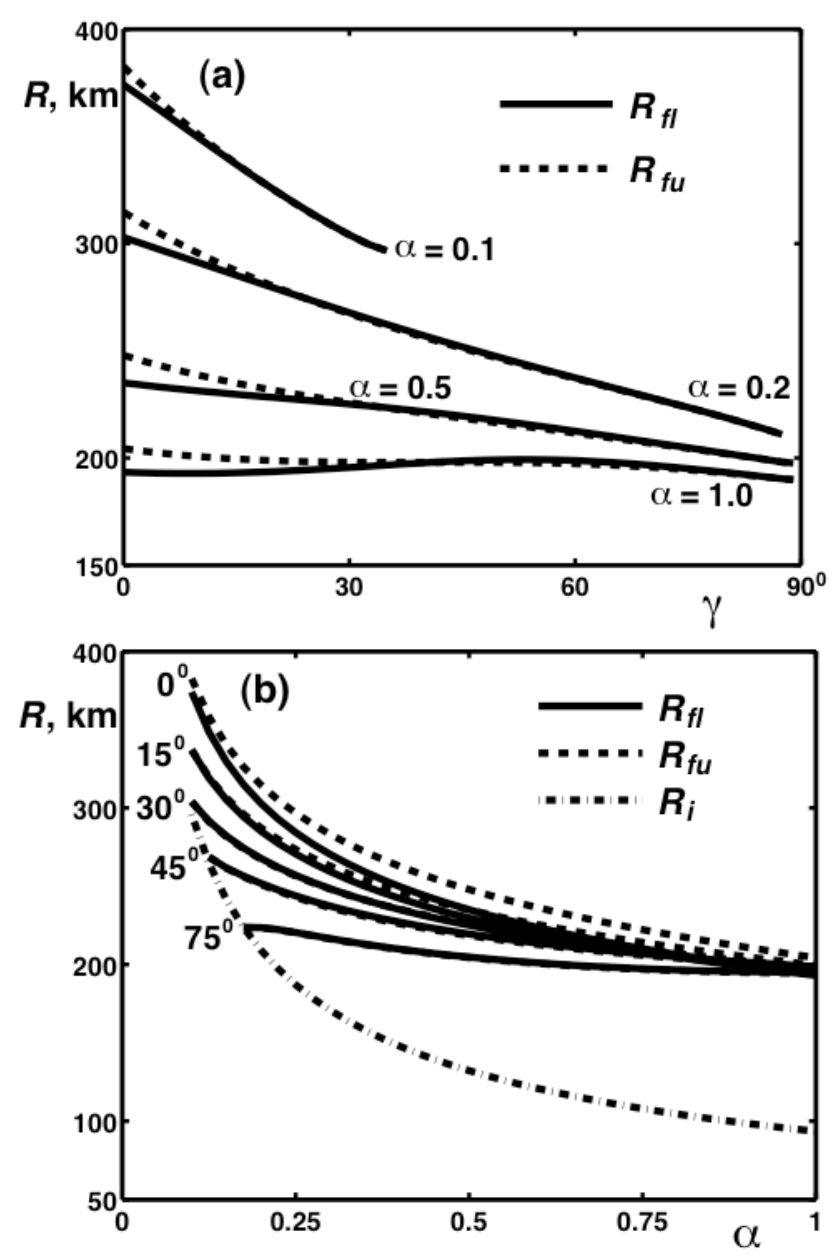

Fig. 3. The theoretical solutions. (a) $R_{f l}$ (solid lines) and $R_{f u}$ (dashed lines) plotted against the angle $\gamma$. Each pair of intersecting curves is marked by a corresponding value of $\alpha$. (b) $R_{f l}$ (solid lines), $R_{f u}$ (dashed lines), and $R_{i}$ (dash-and-dotted line) plotted against $\alpha$. Each pair of divergent curves is marked by a corresponding value of $\gamma$. It is seen that the curves corresponding to $\gamma \geq 45^{\circ}$ start from the $R_{i}$ curve. Note that lines depicting $R_{f l}$ and $R_{f u}$ for $\gamma \geq 30^{\circ}$ almost coincide. In both plots: $h_{0}=0$, $\beta=2.3 \times 10^{-11} \mathrm{~m}^{-1} \mathrm{~s}^{-1}$. Intersection of lower and upper boundaries in panel (a) defines the critical angle.

a nearly meridional wall $\left(\gamma \rightarrow 90^{\circ}\right)$. This was expected because in this case $C_{\xi} \rightarrow 0$. Indeed, the curves of $C_{\xi}$ converge monotonically to zero for each value of $\alpha$ except 0.1 . Intersection of curves corresponding to lower and upper boundaries is seen in Fig. 4a; in Fig. 4b, such curves are converging. Therefore, Figs. 3 and 4 suggest that eddy detachment becomes restricted when $\gamma$ exceeds critical values.

\subsection{Mass flux into the eddies}

We will now estimate the ratio of the mass flux going into the rings and the incoming flux $(\Phi)$. Because $\Phi$ depends 

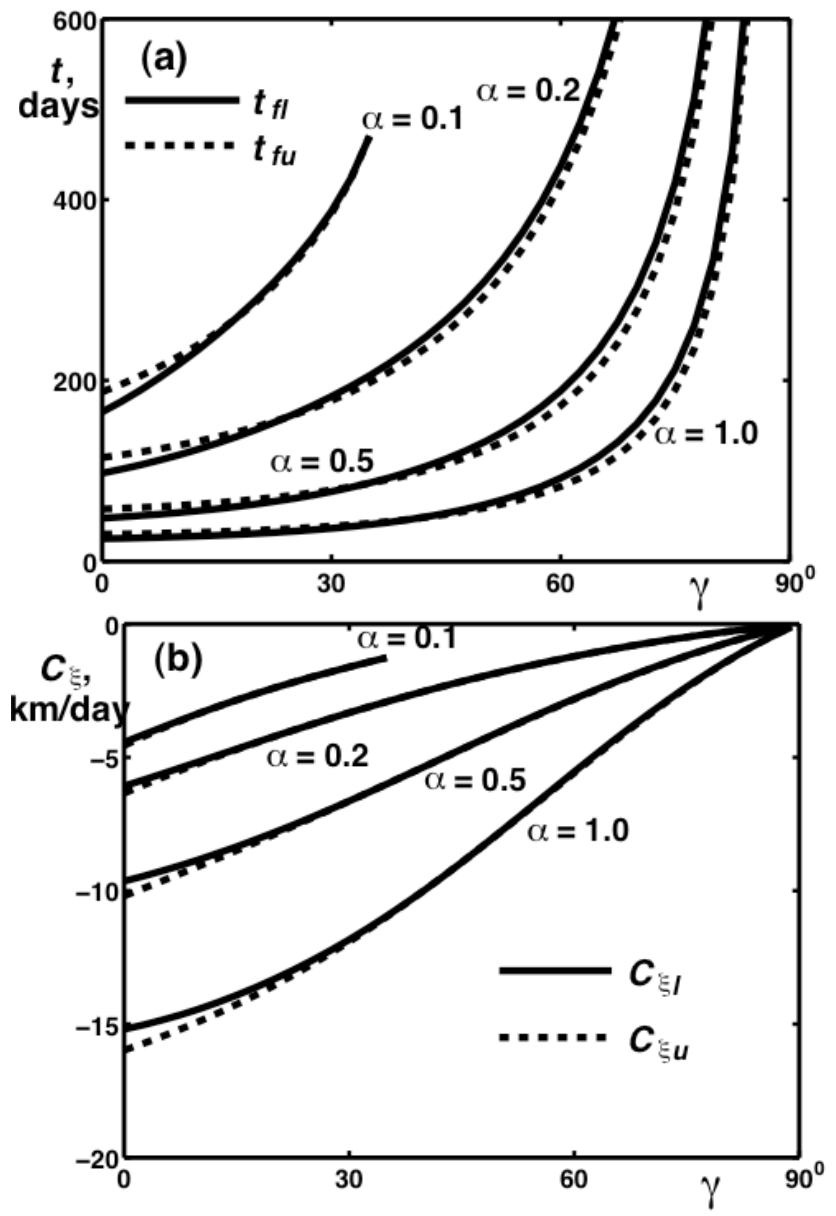

Fig. 4. As in Fig. 3, but for the detachment period and migration rate. (a) Graphs of $t_{f l}$ (solid lines) and $t_{f u}$ (dashed lines). (b) Graphs of $C_{\xi l}$ (solid lines) and $C_{\xi u}$ (dashed lines) against the angle $\gamma$ for the same values of $\alpha$ as in Fig. 3a. At the critical points, the solid and dashed lines intersect (panel a) and converge (panel b).

on time, it is obtained by averaging instant values over the period of eddy generation, i.e.

$\Phi_{l}=t_{f l}^{-1} \int_{0}^{t_{f l}} \Phi d t, \quad \Phi_{u}=t_{f u}^{-1} \int_{0}^{t_{f u}} \Phi d t$.

Since $\Phi$ grows monotonically with time only when $\gamma=0^{\circ}$ and decreases for all other angles, we expect the (averaged) value for $\gamma=0^{\circ}$ to be greater for longer period of formation, namely, $\Phi_{u}>\Phi_{l}$. Otherwise, when the wall is nonzonal, greater averaged values are expected for shorter periods, namely, $\Phi_{u}<\Phi_{l}$. However, when the slant becomes supercritical (for which $R_{f u}<R_{f l}$ and $t_{f u}<t_{f l}$ ), $\Phi_{u}$ again becomes greater than $\Phi_{l}$. This is clearly demonstrated in Fig. 5 showing $\Phi$ versus $\gamma$ for different $\alpha$ (Fig. 5a), and as functions of $\alpha$ for different $\gamma$ (Fig. 5b). We plotted here the "deadline" by analogy with Fig. 5 in ZN, meaning that the
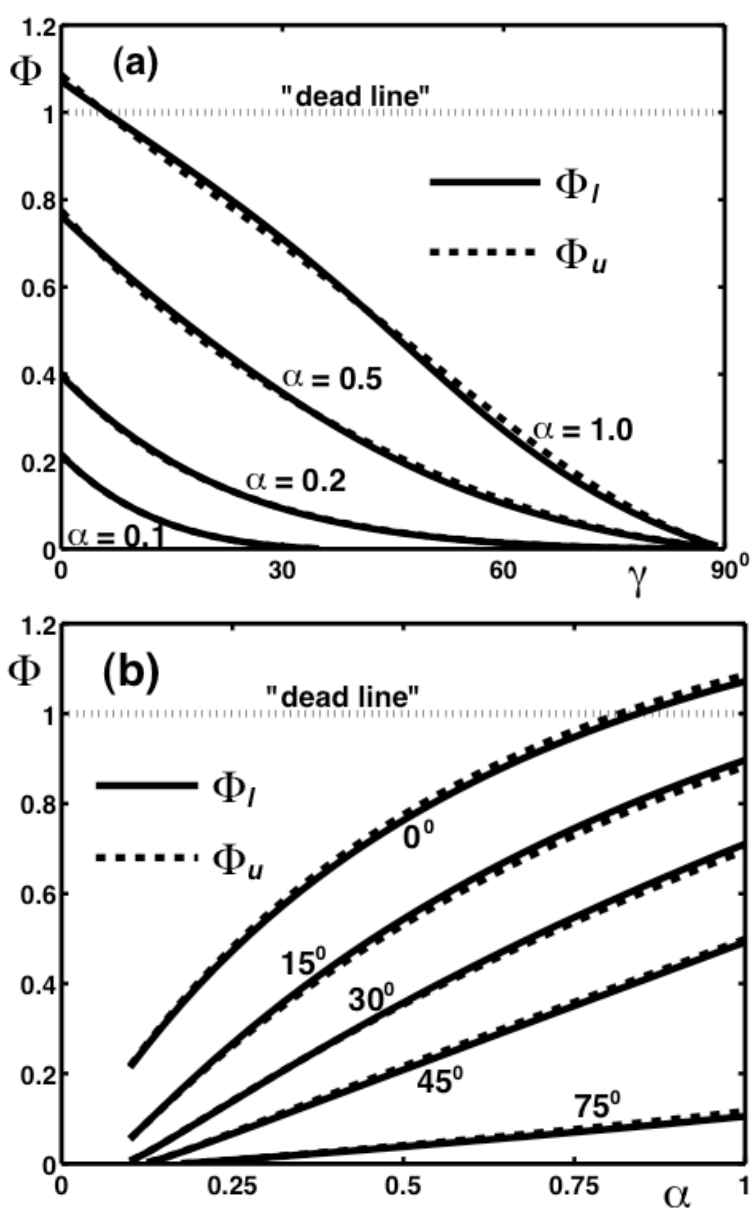

Fig. 5. Theoretically based plots of $\Phi_{l}$ (solid lines) and $\Phi_{u}$ (dashed lines): (a) against the angle $\gamma$ for the same values of $\alpha$ as in Fig. 3a; (b) against $\alpha$ for the same values of $\gamma$ as in Fig. 3b. The "dead lines" are the same as in Fig. 5 of $\mathrm{ZN}$. As before, $h_{0}=0$, and $\beta=2.3 \times 10^{-11} \mathrm{~m}^{-1} \mathrm{~s}^{-1}$.

"vorticity paradox" occurs in the area above this line. As expected, averaged values of $\Phi$ increase with $\alpha$ and decrease with $\gamma$.

The curves of $\Phi_{u}$ and $\Phi_{l}$ in Fig. 5a decrease monotonically to zero, and intersect each other at the point corresponding to $\gamma$ between $1.5^{\circ}$ and $2.5^{\circ}$. For $\gamma \geq 6^{\circ}$, all the curves are below the deadline. Note that, in the case of $\alpha=0.1$, the curves reach zero when the corresponding curves of $R_{f l}$ and $R_{f u}$ in Fig. 3a are terminated. In Fig. 5b, $\Phi$ increases with $\gamma$; for $\gamma=0^{\circ}$ (zonal wall), the corresponding curves cross the deadline for $\alpha \approx 0.8$, and when $\gamma \geq 15^{\circ}$, they are below the deadline everywhere. The rate of increase in $\Phi$ gradually diminishes with increasing $\gamma$.

Typical Agulhas rings have the radius of about $140 \mathrm{~km}$ and radial velocity of about $1 \mathrm{~m} / \mathrm{s}$ (Olson et al., 1985; van Ballegooyen et al., 1994; McDonagh et al., 1999; van Aken et al., 2003; Lutjeharms, 2006). Consequently, the typical value 
of $\alpha$ for the AC is about 0.08. Accordingly, Fig. 5b suggest that $\Phi$ is roughly 0.16 for $\gamma=0$ and 0.035 for $\gamma=20^{\circ}$, meaning a transport of 11.2 and $2.45 \mathrm{~Sv}$ per year. (Equivalently, if 5 rings are shed, the transport is 2.24 and $0.49 \mathrm{~Sv}$ per ring, respectively.) This is consistent with estimates of volume fluxes between 0.4 and 3.0 Sv per ring (de Ruijter et al., 1999).

\subsection{Varying $h_{0}$ and $\beta$}

As mentioned, the influence of increasing $h_{0}$ on the eddy radii is not significant. When we use $h_{0}=300 \mathrm{~m}$ instead of zero, the decrease in $R_{f l}$ and $R_{f u}$ with $\gamma$ becomes slightly more rapid. In the case $\alpha>0.1$, the values (for $\gamma=0^{\circ}$ ) are about 10\% less than in Fig. 3a; they are between 170 and $175 \mathrm{~km}$, when $\gamma \rightarrow 90^{\circ}$. The $300 \mathrm{~m}$ thickness values of $R_{f l}$ and $R_{f u}$ at the point of termination for $\alpha=0.1$ are nearly $245 \mathrm{~km}$ (instead of $295 \mathrm{~km}$ for $h_{0}=0$ ). Increasing $h_{0}$ increases the period of eddy generation. The increase in $t_{f l}$ and $t_{f u}$ with increasing $\gamma$ occurs slower, and for $h_{0}=300 \mathrm{~m}$, the periods are reduced by $10 \%$ for $\gamma=0^{\circ}$ and by $60 \%$ for $\gamma=60^{\circ}$ (Fig. 4a). Finally, the influence of $h_{0}$ on the averaged values of $\Phi$, as well as on the velocities of detached eddies, is marginal.

Increasing $\beta$ leads to quantitative changes. When we use its magnified value (i.e. $6 \times 10^{-11} \mathrm{~m}^{-1} \mathrm{~s}^{-1}$ ), the final eddy radius is reduced by about $20 \%$. The detachment periods are reduced by approximately $60 \%$. The reduction in $\Phi$ does not exceed $10 \%$, and the velocity of the detached eddies roughly double. Despite the reduction, the final radii are still greater than the typical observational values (see ZN, Sect. 1), unless the potential vorticity (PV) is very small (i.e. $\alpha$ is nearly one). For example, when $\gamma=15^{\circ}$ and $\alpha=0.15$, then $R_{f l}$ and $R_{f u}$ are both approximately $256 \mathrm{~km}$, but they change to 144 and $146 \mathrm{~km}$, respectively, when $\alpha$ increases to unity. At the same time, $t_{f l}$ and $t_{f u}$ change from 82 to 10 and 11 days, respectively. Therefore, when the eddies PV is nearly zero, the magnified value of $\beta$ gives noticeably reduced values for the detachment period, which naturally is 60-90 days (Byrne et al., 1995; Schouten et al., 2000).

\section{Numerical model simulations}

\subsection{The numerical model}

We used the Bleck and Boudra (1986) reduced gravity isopycnic model, the description of which was presented in $\mathrm{ZN}$. Here we comment only on the simulation of the detached eddies. We initialized the retroflection from a point along the wall that was about $300 \mathrm{~km}$ north of the termination of the continent. Our modeled time was long (about 210 days) so even when the eddies' PV was initially small, it was ultimately altered significantly by the cumulative effects of friction during the experiment. Therefore, in our quantitative comparisons, we always obtained data for nonzero PV and averaged the values of $\alpha$ over time.

\subsection{Varying the slant}

To accelerate the detachment of the rings and make our runs more economical we chose the magnified value of $\beta$ for most of our experiments. In the experiments with a natural $\beta$, the period of detachment usually exceeded 200 days but qualitative differences in the evolution of the $\mathrm{BE}$, caused by changing $\beta$, were not noted.

(i) Zonal coastline: As mentioned, in the case of zonal incoming current, we were obliged to take a high value for the viscosity coefficient. Although we fixed the parameters so that we can plot the thicknesses every ten days, the starting value of $\alpha=1$ had already approached 0.4 by the time of fixing the parameters for the first plot. At that point, we identified a chain of four eddies that begun to move along the wall. During the simulation time, the first three eddies quickly weakened, but the fourth kept its intensity. At the same time, the latter gradually changed the direction of its movement and shifted away from the wall. Fortunately, we were able to approach the situation when $\Phi$ was almost unity; in this case, nearly all the incoming mass flux contributed to eddy formation. When we started with smaller values of $\alpha$, we also obtained weakening and separation of some eddies, although these effects were not that pronounced.

(ii) Sub-critical slant: The calculations for $\gamma=15^{\circ}$ required a relatively large viscosity coefficient of $1000 \mathrm{~m}^{2} \mathrm{~s}^{-1}$. (This is typical for numerous published eddy experiments using the Bleck and Boudra model.) For $h_{0}=0$, we obtained the detachment of two eddies, which formed a chain downstream (Fig. 6). Before the chain formation, however, the first detached eddy was absorbed by a second one that came from behind and propagated faster. This was followed by the splitting of the merged eddies into two.

We will see later that the re-absorption of the first eddy occurs when $\gamma$ is large. However, in those cases, the reabsorption ultimately results in a return of the first eddy into the retroflection area. For small $\gamma$, the occasional recapturing and splitting of eddies in the model was also found in the ocean (Goni et al., 1997). Hence, in our simulations, the process may either be real, or an effect of the large viscosity coefficient. To check this further, we prolonged the calculation so that the modeled time reached 700 days. Interestingly, we found that the occasional re-capturing and splitting of eddies continued. Despite the increased viscosity, the first two eddies ultimately left the generation area, and a chain of five eddies was displayed behind.

For $h_{0}=300 \mathrm{~m}$, we obtained a somewhat different situation. The detached eddies formed a chain with no re-capturing; however, while the first eddy was intense, the 

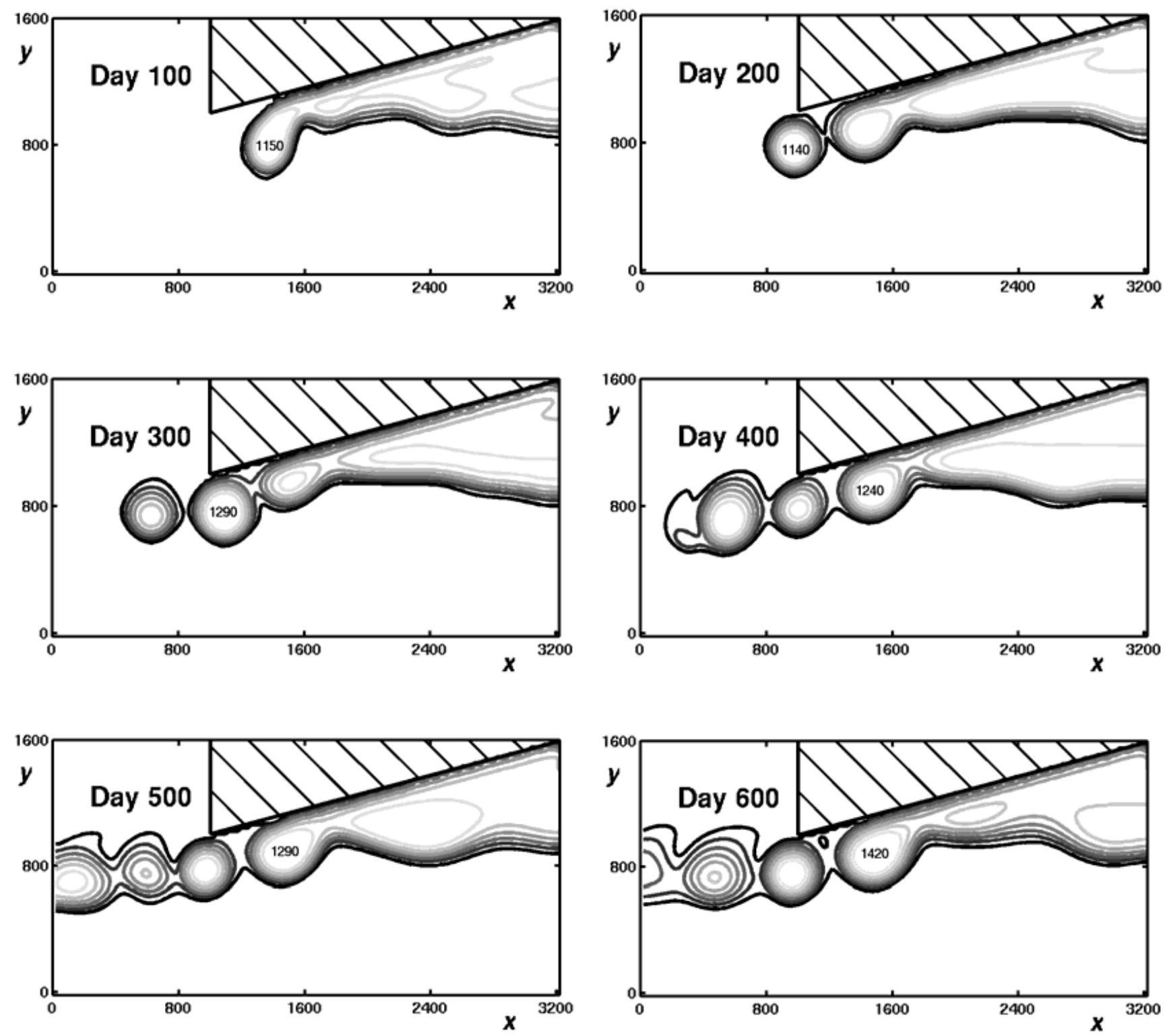

Fig. 6. Thickness contours of the numerical simulation for the first 600 days. A chain of eddies is formed despite intermittent cases of eddies recapturing. Numerical values: $\gamma=15^{\circ}, \alpha=1, h_{0}=0$, and $\nu=1000 \mathrm{~m}^{2} \mathrm{~s}^{-1}$. Spacing between contours represents increments of $200 \mathrm{~m}$, and the maximal thickness of the upper layer is given in meters. The $x$ and $y$ scales are in kilometers. Note that we used $\beta=6 \times 10^{-11} \mathrm{~m}^{-1} \mathrm{~s}^{-1}$ here and in all the following figures.

remaining eddies behind were significantly weaker. Similar effects can be seen for lower starting values of $\alpha$, but the time of eddy development is, as expected, longer.

(iii) Near-critical slant: In contrast to the theoretical calculations, simulations using $\gamma=30^{\circ}$ and $\gamma=45^{\circ}$ produced eddies that propagated more freely than those in the case of $\gamma=15^{\circ}$. One possible explanation lies in our use of the lower viscosity coefficient of $700 \mathrm{~m}^{2} \mathrm{~s}^{-1}$ in the first case. The radius of the first detached eddy increased only in our simulation for $\gamma=30^{\circ}, \alpha=0.1$, and $h_{0}=300 \mathrm{~m}$, which could be an effect of the long period of detachment. In all other cases, the radii clearly decreased. This could be one of the main factors responsible for maintaining the distances between the rings and protecting them from re-absorption. It is difficult to say whether this was a consequence of vanishing possible (theoretical) range of the final radius, frictional forces, or both. In any case, we conclude that the possibility of an eddy chain formation for such slants is questionable. For a prolonged numerical simulation, the frequency of ring 

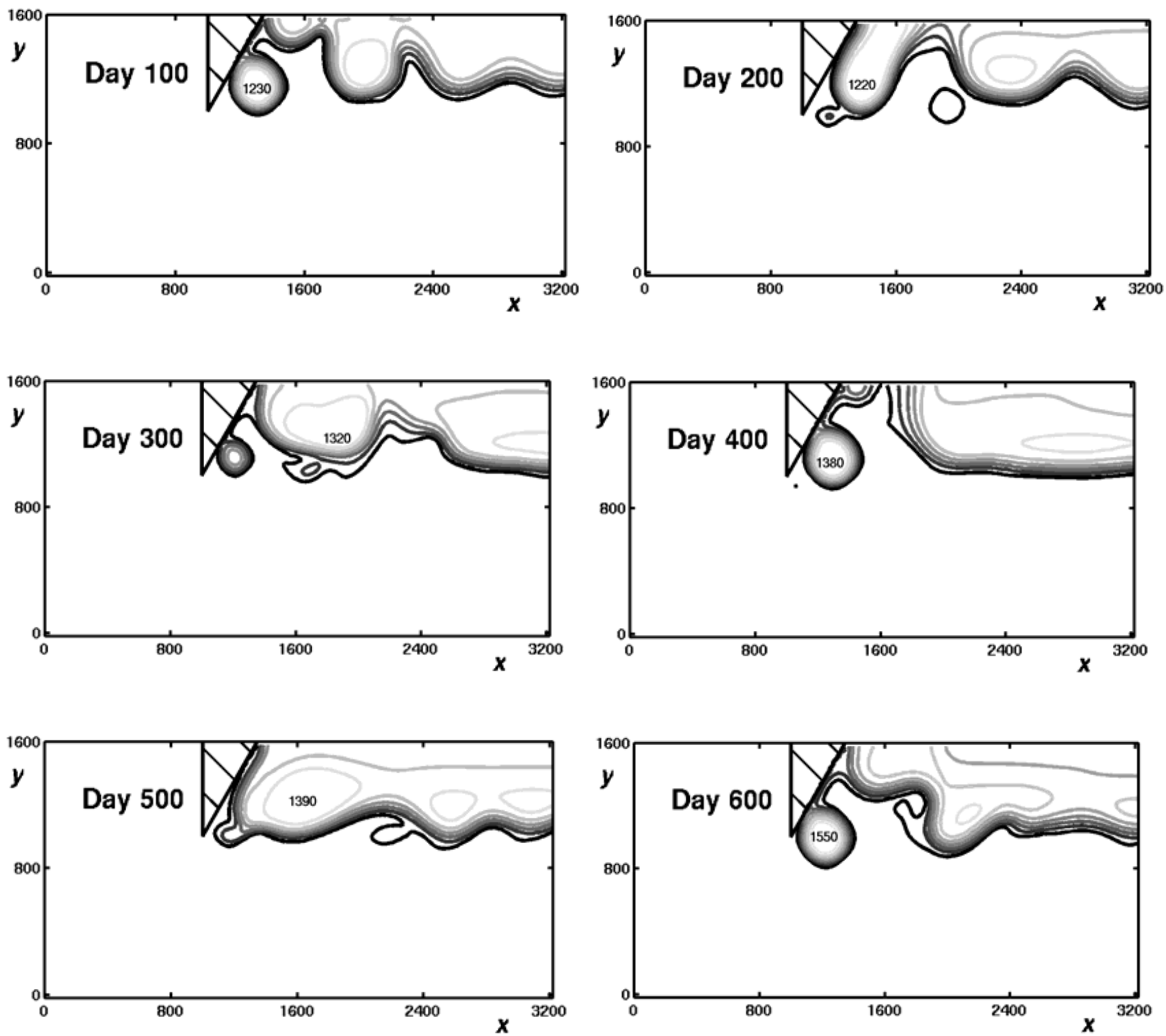

Fig. 7. The same as Fig. 6, but for $\gamma=60^{\circ}, \alpha=1, h_{0}=0$, and $\nu=700 \mathrm{~m}^{2} \mathrm{~s}^{-1}$. The initially detached eddy is re-captured by the incipient meander. The merged eddies then detach but are re-captured again later; this process repeated itself 3-4 times. The eddy shown in day 600 was later re-captured by day 700 but this recapturing is not displayed in the figure.

re-capturing increased with time; as a result, after 700 days of simulation, only two rings propagated around the cape.

(iv) Super-critical slant: Simulations with a slant of $60^{\circ}, 75^{\circ}$, and $90^{\circ}$ clearly confirmed the super-criticality. In some cases, such as that of $\gamma=60^{\circ}, \alpha=1$, and $h_{0}=300 \mathrm{~m}$, we did not see a detachment at all. Instead, a meander of relatively high, but variable, intensity appeared. Other simulations using $\gamma=75^{\circ}, \alpha=1$, and $h_{0}=0$, showed almost a complete damping of the first eddy, which remained stationary after its detachment. The most typical situation is shown in Fig. 7 (for $\gamma=60^{\circ}, \alpha=1$, and $h_{0}=0$ ). After detachment, the first eddy gradually decayed before being recaptured by the meandering retroflected current behind. We note that such a scenario is similar to the behavior of rings detached from the retroflection of the EAC, described by Nilsson and Cresswell (1981), and Sokolov and Rintoul (2000). We can say, therefore, that, starting from $\gamma=60^{\circ}$, the formation of a stable chain of eddies becomes impossible. To confirm this, we further extended our simulations, so that the modeled time reached 700 days. As a result, the absorbing meander of the retroflecting current was transformed into an eddy 

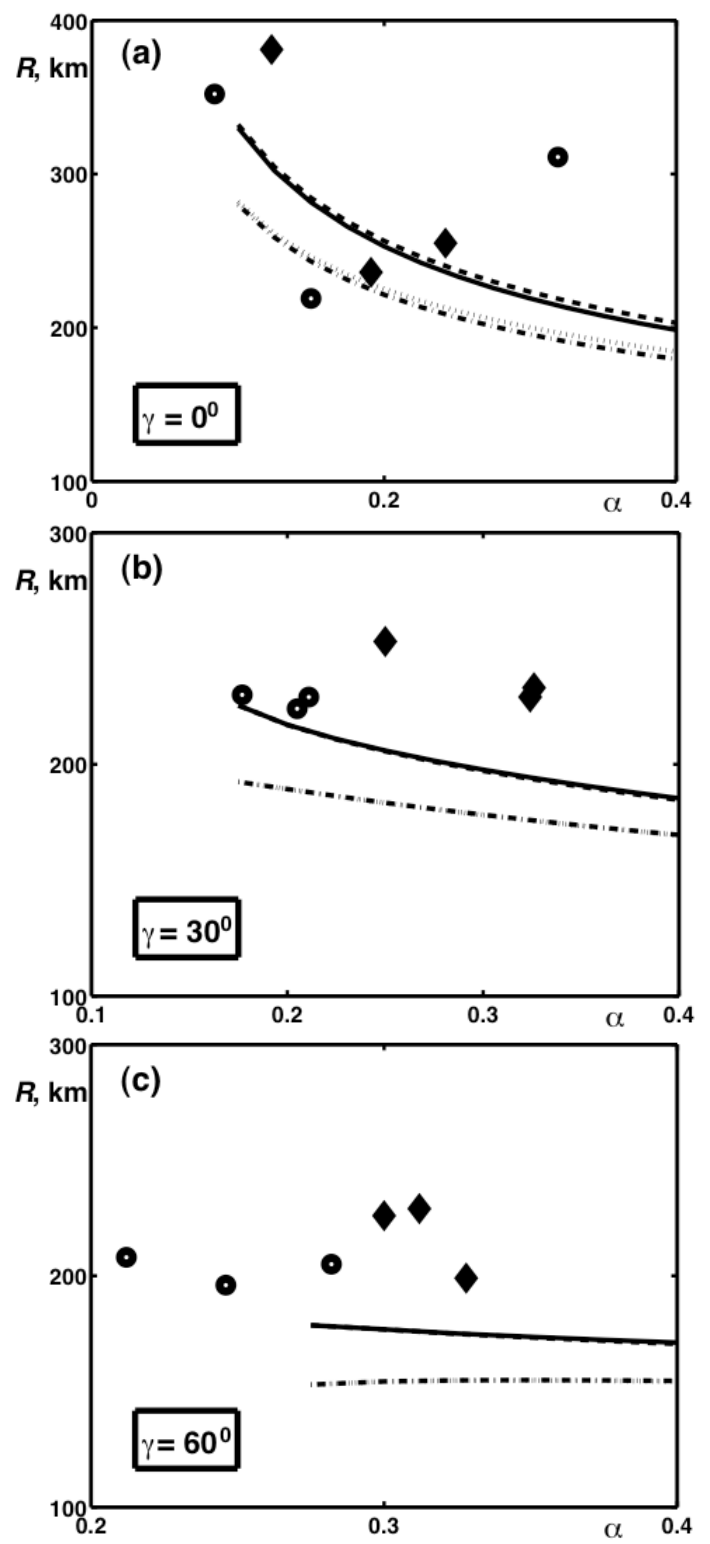

Fig. 8. Comparison of modeled radii with the numerics. The modeled values of $R_{f l}$ and $R_{f u}$ are plotted against $\alpha$ for $h_{0}=0$ (solid and dashed lines, respectively) and for $h_{0}=300 \mathrm{~m}$ (dash-and-dotted and dotted lines, respectively). The numerical values of $R$ correspond to $\alpha$ averaged over the time of the experiments (diamonds for $h_{0}=0$ and circles for $h_{0}=300 \mathrm{~m}$ ). Here: (a) $\gamma=0^{\circ}$, and the theoretical curves start from $\alpha=0.1$; (b) $\gamma=30^{\circ}$; (c) $\gamma=60^{\circ}$. The theoretical curves start from the points at which $R_{f l}=R_{i}$ or $R_{f u}=R_{i}$. The curves of $R_{f l}$ and $R_{f u}$ are overlapping in panels (b) and (c) because the angle of $30^{\circ}$ is near-critical and $60^{\circ}$ is supercritical.

that was shed. However, later on, it was re-captured by the meander, just as the first detached eddy was. Such a process of shedding and re-capturing was repeating, and no eddies left the retroflection area. (The eddy shown in Fig. 7 for day 600 was later re-captured by day 700.) In view of this, we suggest that, for such values of the slant, re-capturing becomes systematic and overwhelms the formation of the chain of eddies.

We should comment here about the situation when $\alpha$ is small. Our simulations with $\alpha=0.1$ and $\gamma=60^{\circ}$ and $75^{\circ}$ qualitatively confirmed our theoretical prediction that the eddy cannot grow because the $\beta$-induced force initially exceeds the combined force of the currents (i.e. their long-shore momentum flux). In such cases, the plots showed the formation of a meander that was gradually forced into the wall. Its longitudinal dimension, along the wall, became much greater than the transverse one, negating our assumption of a nearly circular form. Eventually, an eddy of a smaller radius was formed from this meander. Further, the formed eddy continued decaying and exhibited almost no movement. We expected that it would finally be reabsorbed, but we did not reach that state.

\subsection{Simulation-theory comparison}

In addition to the qualitative analysis of ring behavior discussed above, we carried out a detailed comparison of the theoretical modeling and the numerical simulations. (For this purpose, we used the magnified value of $\beta$.) We compared the eddy radius at the moment of detachment, $R_{f}$, the eddy propagation velocity $\left(C_{\xi}\right)$, and the ratio of the mass flux going into the eddies and the incoming flux $(\Phi)$.

Two introductory comments should be made here. First, Nof and Pichevin (2001, NP, hereafter) carried out the quantitative comparison of the ratio $q / Q$ as a function of time, where $q$ is outgoing mass flux. In their case, it was very important to take into account the time evolution of the parameter $\alpha$, which was dramatically altered by the viscosity in the numerics. For us, it was inconvenient to conduct a similar analysis because $\Phi$ was also variable in time, and we were operating mainly with its time-averaged values. Therefore, we simplified our analysis by assuming that the value of $\Phi$, averaged over the time of the numerical experiment, corresponded to the value of $\alpha$ averaged in the same way, and so did with the other parameters that we considered. Second, we also averaged the value of $C_{\xi}$. Wherever possible, we used an averaging period between the moment of detachment and the last step in our experiment. However, in most simulations with supercritical values of $\gamma$, we were obliged to use a period between the detachment and the re-absorption of the eddy.

According to NP, the coefficient $\alpha$ decreases quickly when its initial value is unity (zero PV). In the case of finite PV outflow, $\alpha$ decreases more slowly. However, in most of the experiments that started with $\alpha=0.1$, we observed a slight growth in $\alpha$, especially for large $\gamma$. Most likely, this was a consequence of a decrease in the size of the meander/eddy due to $\beta$. Resulting from the above-mentioned behaviors of $\alpha$, its average value accumulated in relatively narrow 
intervals: between 0.12 and 0.36 for $h_{0}=0$, and between 0.08 and 0.33 for $h_{0}=300 \mathrm{~m}$.

Figure 8 shows a comparison of $R_{f}$ in the analytics and numerical simulations. Bearing in mind that the starting values of $\alpha$ in the numerics were $1,0.4$, and 0.1 , we mark the numerical results for the time-averaged values of $\alpha$ with circles and diamonds. Analyzing Fig. 8a, b, and c, where $\gamma$ is $0^{\circ}, 30^{\circ}$ and $60^{\circ}$ (respectively), we see that the numerical simulations confirm the theoretical tendency for the radius to decrease with growing angle. However, such a decrease is weaker than in the theoretical prediction. In this connection, the scattering in $R_{f}$ weakens with $\gamma$. Strictly speaking, our theory does not allow us to estimate $R_{f}$ corresponding exactly to the $\alpha$ obtained in the numerics when $\gamma$ is large, because under such conditions, the BE is forced into the wall. We conclude that, for nonzero $\gamma$, the numerical radii calculations give larger values than our theoretical model (by about 20-30\%) probably due to friction which caused the eddies to flatten out. In the case of a zonal wall, the agreement is better overall, but the scattering of numerical values is significant.

Figure 9 shows a comparison of the theoretical and numerical values of $C_{\xi}$ for $\gamma=0^{\circ}, 30^{\circ}$, and $60^{\circ}$, whereas Fig. 10 shows the comparison of $\Phi$ for the same angles. (We note that there are two circles instead of three in the lower panel of Fig. 9. This is because, as mentioned, in our simulation with $\gamma=60^{\circ}, \alpha=1$ and $h_{0}=300 \mathrm{~m}$ we did not achieve detachment, so we could not compute the eddy drift velocity.) The agreement of $C_{\xi}$ is poor for $\gamma=0$, which could be a result of very large viscosity in our numerics, leading to strong deceleration of eddies. This agreement improves with growing $\gamma$ for $h_{0}=0$; in the case of $h_{0}=300 \mathrm{~m}$ it is worse because of the noticeable scattering in the numerical values. Nevertheless, we can suggest that Fig. 9 confirms Eq. (3), which was introduced without any rigorous analysis.

The agreement seems to be not very good with regard to $\Phi$, especially for nonzero $\gamma$. However, it is not easy to compute the mass flux numerically because of noise (e.g. in the form of Kelvin waves and secondary meandering of the outgoing flow, and frictional effects) leading to ambiguity in the boundaries of this flux. The scattering of the numerical values ranges between slightly negative and about 0.18 , which is admissible when the theoretical values are between zero and 0.2 (for $\gamma=30^{\circ}$ ), or even between zero and 0.05 (for $\gamma=60^{\circ}$ ). In either case, the numerics clearly confirm that $\Phi$ is considerably smaller when the coastline is slanted.

\section{Summary and conclusions}

The main aim of our theoretical and numerical analyses was to examine the hypothesis that the glacial $\mathrm{AC}$ was similar to the present day EAC where, due to the orientation of the coastline, no mean rings shedding is usually observed. According to our hypothesis, the shedding of eddies is severely restricted when the slant angle $\gamma$ is about $65^{\circ}$ (the present
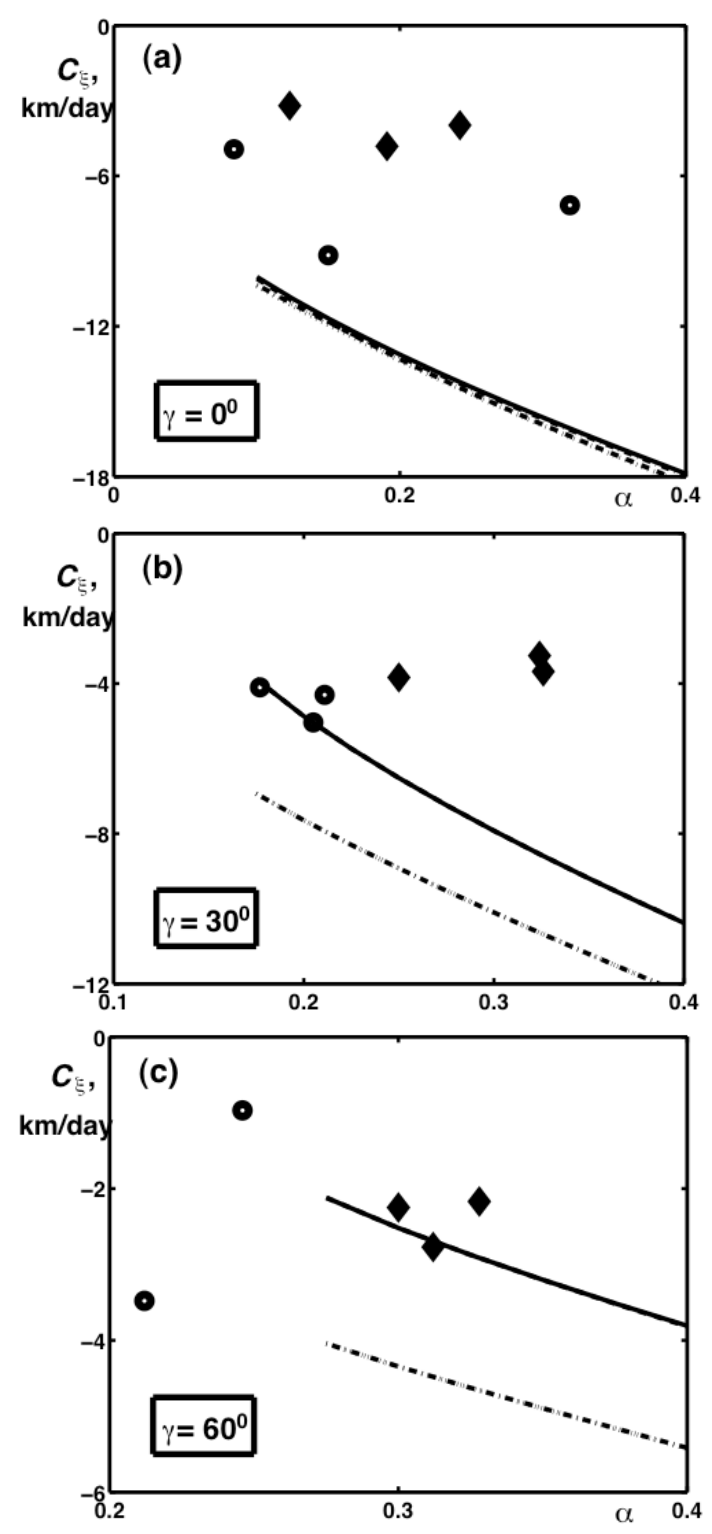

Fig. 9. As in Fig. 8 except that this is a comparison of the modeled propagation rates with the numerics.

EAC, and the glacial AC) and greater, but occurs steadily when $\gamma$ is smaller than about $20^{\circ}$ (present AC).

To examine this hypothesis we developed a non-linear model of retroflecting currents that flow along slanted coastlines. We studied the dependence of ring diameter, speed and frequency of shedding, on the coastline slant, the PV of the formed eddies, and the thickness of the surrounding upper layer. The results are shown in Figs. 3-5. We treated the angle of visible intersection of the lower and upper boundaries of the theoretical eddy radius (Fig. 3) as the critical angle. Indeed, according to our definition of the lower boundary (osculating rings), the convergence of the lower and upper 

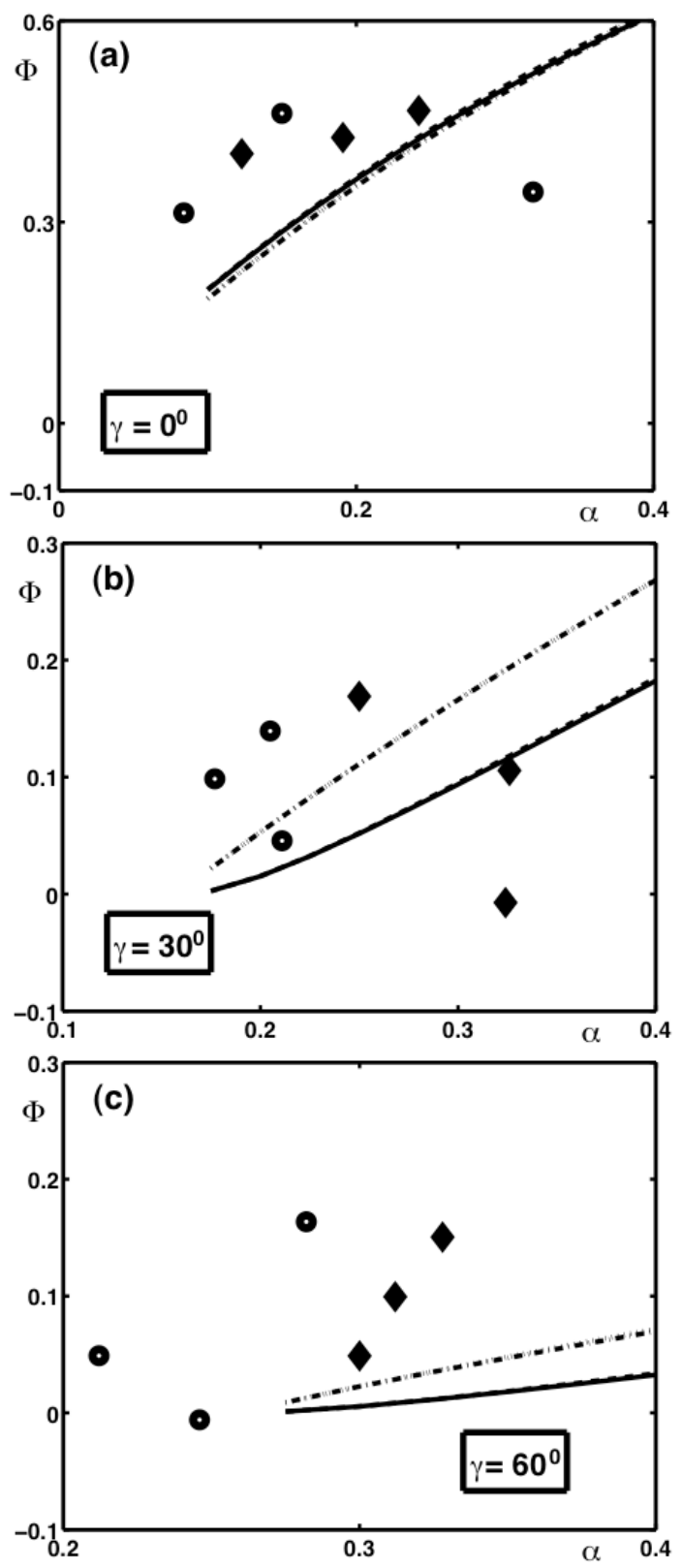

Fig. 10. As in Fig. 8 except that we show here a comparison of the mass flux ratio $(\Phi)$.

boundaries means that only a chain of "kissing" detached rings can form downstream. This implies that, in practice, the rings are likely to hinder each other owing, for instance, to viscosity. Because for supercritical slants, small long-shore drift speeds are predicted for detached rings, the slowly moving eddy will be hindered and re-captured by the one behind it or by a meander of the retroflected current. Such a scenario agrees well with the dynamics of the EAC rings described by Nilsson and Cresswell (1981), and Sokolov and Rintoul (2000). These rings usually stay at the same place for a long time and may eventually re-coalesce with the EAC.
We used a modified version of the Bleck and Boudra (1986) reduced gravity isopycnic model and obtained plots surprisingly similar to the observed EAC dynamics when the slant was taken to be $60^{\circ}$ or more (Fig. 7). Also, as expected, we obtained chains of detached eddies when the slant was $15^{\circ}$ (Fig. 6) and, a less clear chain when $\gamma=30^{\circ}$. The transition range of slant angles was between $25^{\circ}$ and $50^{\circ}$, which agrees with our description of the critical angle that is approximately $18^{\circ}, 25^{\circ}, 33^{\circ}$, and $40^{\circ}$ when $\alpha$ is $0.1,0.2,0.5$, and unity (respectively). During most of our simulation, $\alpha$ was between 0.15 and 0.3 and the variables obtained in the theoretical modeling were in satisfactory quantitative agreement with our numerical simulations (Figs. 8-10). On this basis, we suggest that the significant reduction in the exchange between the Indian and South Atlantic Oceans during the glacials and the YD was due to a northward migration of the WSC. This led the AC retroflection area to shift to a latitude of a supercritical coastal slant (Fig. 1). Other important results of our study can be summarized as follows:

- An increase in $\gamma$ leads to a decrease in the radii of detached rings and makes them less sensitive to variations in $\alpha$ (Fig. 3). Nevertheless, even in the case of supercritical slant, the theoretical values of $R_{f}$ are $185-220 \mathrm{~km}$ and, therefore, still noticeably greater than the observational values.

- The mass-flux ratio $\Phi$ decreases monotonically with increasing coastal slant (Fig. 5). When $\gamma \geq 6^{\circ}$, it becomes less than unity (even for eddies with zero PV, i.e. intense eddies) implying that the "vorticity paradox" discussed by $\mathrm{ZN}$ is circumvented.

- Our assumption of a nearly circular BE fails when the PV is large (weak eddies) and $\gamma$ is not very small. In that case, the BE does not grow; rather, it is forced into the wall and deforms.

Concerning the distance between two consecutive eddies, we note that the ratio $R_{f u} / R_{f l}$ is maximal in the case of zonal wall, when it is approximately 1.06 (i.e. less than $2^{1 / 5}$ ). Therefore, we conclude that, theoretically, the separation distance should not exceed the eddy diameter. This conclusion is not far from the observational data, even though the eddy diameter is smaller than our theory yields. Indeed, if the eddies are shed on average 5 times per year, and their migration rate varies between 2 and $10 \mathrm{~cm} / \mathrm{s}$, then, during the period of generation, the eddy migrates $380 \mathrm{~km}$ on average, and at the most $630 \mathrm{~km}$. Taking into account a typical eddy radius of $140 \mathrm{~km}$, we obtain that the ratio $(d / 2 R)$ is 0.36 in average, with a maximal value of 1.25 .

As is frequently the case, our ability to compare our theoretical results with the numerical simulations was limited due to the effect of viscosity in the numerics, which led to a relatively narrow range of $\alpha$. In addition, the viscosity in the numerics makes the outgoing flux blurry, resulting in a 
possibility of errors as large as 0.2 in the determination of $\Phi$. Despite both of these aspects, our comparison is useful. Although in our numerical simulations we confirmed the observation that re-capturing and re-splitting of eddies can be a possible cause of non-regularity in their shedding (Goni et al., 1997), we find that non-regularity could also be connected with variability of the retroflection position (Lutjeharms, 2006). For example, we note that Esper et al. (2004) pointed out seasonality of its position.

Our results also agree with Chassignet and Boudra's (1988) sensitivity analysis, which showed that decreasing coastal slant leads to an increase in the production of rings. On the other hand, the numerical experiments by Pichevin et al. (1999) showed that the dependence of the periodicity of rings shedding on the slant angle could be negligible. This might be a result of the specific geometry of coastline in their model. We leave this issue as a subject for future investigations. Finally, we note that taking into account the coastline slant could also improve understanding of other retroflecting oceanic currents such as the North Brazil Current (NBC). Unfortunately, the question of a priori determination of the eddy PV remains unanswered, and this is significant particularly when the vorticity of the incoming fluid is cyclonic rather than anticyclonic.

\section{Appendix A}

\section{List of symbols}

$\begin{array}{ll}\text { AAIW } & \text { Antarctic Intermediate Water } \\ \text { AC } & \text { Agulhas Current } \\ \text { BE } & \text { basic eddy } \\ C_{x} & \text { eddy velocity in the open ocean } \\ C_{\xi} & \text { eddy migration rate along the slanted coast } \\ C_{\xi f} & \text { eddy migration rate after detachment } \\ C_{\xi l}, \quad C_{\xi u} & \text { values of } C_{\xi f} \text { for eddies with radii } \\ & R_{f l}, R_{f u}, \text { respectively } \\ d & \text { distance between consecutive eddies } \\ d_{u} & \text { "upper" boundary of } d \\ \text { EAC } & \text { East Australian Current } \\ g^{\prime} & \text { reduced gravity } \\ h_{0} & \text { upper layer thickness at the wall } \\ H & \text { upper layer thickness outside the retroflec- } \\ & \text { tion area } \\ H_{f l}, \quad H_{f u} & \text { values of } H \text { at the moments } t_{f l}, t_{f u}, \text { re- } \\ \text { LGM } & \text { spectively } \\ \text { MOC } & \text { Last Glacial Maximum } \\ \text { NADW } & \text { meridional overturning circulation } \\ \text { NP } & \text { North Atlantic Deep Water } \\ & \text { Nof and Pichevin (2001) }\end{array}$

$\begin{array}{ll}\text { PSU } & \text { practical salinity units } \\ \text { PV } & \text { potential vorticity } \\ Q & \text { mass flux of the incoming current } \\ Q_{R} & \text { volume flux of the rings } \\ q & \text { mass flux of the retroflected current } \\ R & \text { radius of the eddy (a function of time) } \\ R_{i} & \text { initial radius of the eddy } \\ R_{f} & \text { radius of detached eddy } \\ R_{f l}, R_{f u} & \text { "lower" and "upper" boundaries of } R_{f} \\ S & \text { salinity } \\ \mathrm{SA} & \text { Southern Atlantic } \\ \mathrm{SEA} & \text { Southeastern Atlantic } \\ t & \text { time } \\ t_{f} & \text { period of the eddies generation } \\ t_{f l}, t_{f u} & \text { "lower" and "upper" boundaries of } t_{f} \\ \mathrm{WSC} & \text { wind stress curl } \\ \mathrm{YD} & \text { Younger Dryas } \\ \mathrm{ZN} & \text { Zharkov and Nof (2008) } \\ \alpha & \text { vorticity (twice the Rossby number) } \\ \beta & \text { meridional gradient of the Coriolis param- } \\ \gamma & \text { eter } \\ \xi, \eta & \text { slant of coastline } \\ \Phi & \text { axes of rotated moving coordinate system } \\ \Phi_{l}, \Phi_{u} & \text { ratio of mass flux going into the eddies and } \\ & \text { incoming mass flux } \\ & \text { values of } \Phi \text { for eddies with radii } \\ & R_{f l}, R_{f u}, \text { respectively. } \\ & \end{array}$

Acknowledgements. The study was supported by the NASA under the Earth System Science Fellowship Grant NNG05GP65H. V. Zharkov was also funded by the Jim and Shelia O'Brien Graduate Fellowship. Nof acknowledges a detailed and extensive email exchange with Arnold Gordon regarding the salt balance calculation described in Sect. 1.2. We are grateful to Steve van Gorder for helping in the numerical simulations, to Donna Samaan for helping in preparation of manuscript, and to Joanna Beall for helping in improving the style.

Edited by: A. Sterl

\section{References}

Andrews, J. C. and Scully-Power, P.: The structure of an East Australian Current anticyclonic eddy, J. Phys. Oceanogr., 6, 756765, 1976.

Arruda, W. Z., Nof, D., and O'Brien, J. J.: Does the Ulleung eddy owe its existence to $\beta$ and nonlinearities?, Deep-Sea Res., 51, 2073-2090, 2004.

Bard, E.: Climate shock: abrupt changes over millennial time scales, Phys. Today, 55, 32-38, 2002.

Berger, W. H. and Wefer, G.: Expeditions into the past: paleoceanographic studies in the South Atlantic, pp. 35-156, SpringerVerlag, Berlin-Heidelberg, 1996.

Bleck, R. and Boudra, D.: Wind-driven spin-up in eddy resolving ocean models formulated in isopycnic and isobaric coordinates, J. Geophys. Res., 91, 7611-7621, 1986. 
Bostock, H. C., Opdyke, B. N., Gagan, M. K., Kiss, A. E., and Fifield, L. K.: Glacial/interglacial changes in the East Australian current, Clim. Dynam., 26, 645-659, 2006.

Byrne, A. D., Gordon, A. L., and Haxby, W. F.: Agulhas eddies: A synoptic view using geosat ERM data, J. Phys. Oceanogr., 25, 902-917, 1995.

Chassignet, E. P. and Boudra, D. B.: Dynamics of the Agulhas retroflection and ring formation in a numerical model. II. Energetics and ring formation, J. Phys. Oceanogr., 18, 304-319, 1988.

de Ruijter, W. P. M.: Asymptotic analysis of the Agulhas and Brazil Current systems, J. Phys. Oceanogr., 12, 361-373, 1982.

de Ruijter, W. P. M., Biastoch, A., Drijfhout, S. S., Lutjeharms, J. R. E., Matano, R. P., Pichevin, T., van Leeuwen, P. J., and Weijer, W.: Indian-Atlantic interocean exchange: Dynamics, estimation and impact, J. Geophys. Res., 104, 20 885-20 910, 1999.

Esper, O., Versteegh, G. J. M., Zonneveld, K. A. F., and Willems, H.: A palynological reconstruction of the Agulhas Retroflection (South Atlantic Ocean) during the Late Quaternary, Global Planet. Change, 41, 31-62, 2004.

Gasse, F.: Hydrological changes in the African tropics since the Last Glacial Maximum, Quat. Sci. Rev., 19, 189-211, 2000.

Goni, G. J., Garzoli, S. L., Roubicek, A. J., Olson, D. B., and Brown, O. B.: Agulhas ring dynamics from TOPEX/POSEIDON satellite altimeter data, J. Mar. Res., 55, 861-883, 1997.

Gordon, A. L., Lutjeharms, J. R. E., and Gründlingh, M. L.: Stratification and circulation at the Agulhas Retroflection, Deep-Sea Res., 34, 565-599, 1987.

Howard, W. R. and Prell, W. L.: Late quaternary surface circulation of the southern Indian Ocean and its relationship to orbital variation, Paleoceanogr., 7, 79-117, 1992.

Kawagata, S.: Tasman front shifts and associated paleoceanographic changes during the last 250,000 years: foraminiferal evidence from the Lord Howe Rise, Mar. Micropal., 41, 167-191, 2001.

Knorr, G. and Lohmann, G.: Southern Ocean origin for the resumption of the Atlantic overturning circulation during deglaciation, Nature, 424, 532-536, 2003.

Lutjeharms, J. R. E.: The exchange of water between the South Indian and South Atlantic Oceans, in: The South Atlantic: Present and Past Circulation, edited by: Wefer, G., Berger, W., and Sielder, G., pp. 125-162. Springer-Verlag, Berlin-Heidelberg, 1996.

Lutjeharms, J. R. E.: The Agulhas Current, Springer-Verlag, BerlinHeidelberg-New York, XIV, 330 p., 2006.

Martinez, J. I.: Late Pleistocene palaeoceanography of the Tasman Sea: implications for the dynamics of the warm pool in the western Pacific, Palaeogreogr. Palaeoclimatol. Palaeoecol., 112, 1962, 1994.

Martinez, J. I., de Deckker P., and Barrows, T. T.: Palaeoceanography of the western Pacific warm pool during the last glacial maximum: long-term climatic monitoring of the maritime continent, in: Bridging Wallace's line, edited by: Kershaw, P., Bruno, D., Tapper, N., Penny, D., and Brown, J., Adv. Geoecol., 34, 147-172, 2002.

McDonagh, E. L., Heywood, K. J., and Meredith, M. P.: On the structure, paths, and fluxes associated with Agulhas rings, J. Geophys. Res., 104, 21 007-21 020, 1999.

Nilsson, C. S., Andrews, J. C., and Scully-Power, P.: Observation of eddy formation off East Australia, J. Phys. Oceanogr., 7, 659669, 1977.

Nilsson, C. S. and Cresswell, G. R.: The formation and evolution of East Australian Current warm-core eddies, Progr. Oceanogr., 9, 133-183, 1981.

Nof, D.: On the migration of isolated eddies with application to Gulf Stream rings, J. Mar. Res., 41, 399-425, 1983.

Nof, D.: The momentum imbalance paradox revisited, J. Phys. Oceanogr., 35, 1928-1939, 2005.

Nof, D. and Pichevin, T.: The ballooning of outflows, J. Phys. Oceanogr., 31, 3045-3058, 2001.

Nof, D. and Van Gorder, S.: Did an open Panama Isthmus Correspond to an invasion of Pacific water into the Atlantic?, J. Phys. Oceanogr., 33, 1324-1336, 2003.

Olson, D. B. and Evans, R. H.: Rings of the Agulhas Current, DeepSea Res., 33, 27-42, 1986.

Peeters, F. J. C., Acheson, R., Brummer, G.-J. A., de Ruijter, W. P. M., Schneider, R. R., Ganssen, G. M., Ufkes, E., and Kroon, D. Vigorous exchange between the Indian and Atlantic oceans at the end of the past five glacial periods, Nature, 430, 661-665, 2004.

Pichevin, T., Nof, D., and Lutjeharms, J. R. E.: Why are there Agulhas Rings?, J. Phys. Oceanogr., 29, 693-707, 1999.

Rau, A. J., Rogers, J. Lutjeharms, J. R. E., Giraudeau, J., LeeThorp, J. A., Chen, M.-T., and Waelbroeck, C.: A 450-kyr record of hydrological conditions on the western Agulhas Bank Slope, south of Africa, Mar. Geol., 180, 183-201, 2002.

Sandal, C. and Nof. D.: A new analytical model for Heinrich events and climate instability, J. Phys. Oceanogr., 38, 451-466, 2008.

Schouten, M. W., de Ruijter, W. P. M., van Leeuwen, P. J., and Lutjeharms, J. R. E.: Translation, decay and splitting of Agulhas rings in the south-eastern Atlantic ocean, J. Geophys. Res., 105, 21913-21 925, 2000.

Schouten, M. W., de Ruijter, W. P. M., and van Leeuwen, P. J.: Upstream control of the Agulhas ring shedding, J. Geophys. Res., 107, doi:10.1029/2001JC000804, 2002.

Shi, C. and Nof, D.: The destruction of lenses and generation of wodons, J. Phys. Oceanogr., 24, 1120-1136, 1994.

Sokolov, S. and Rintoul, S.: Circulation and water masses of the southwest Pacific: WOCE Section P11, Papua New Guinea to Tasmania, J. Mar. Res., 58, 223-268, 2000.

Speich, S., Lutjeharms, J. R. E., Penven, P., and Blanke, B.: Role of bathymetry in Agulhas Current configuration and behavior, Geophys. Res. Lett., 33, L23611, doi:10.1029/2006GL027157, 2006.

Tilburg, C. E., Hulburt, H. E., O’Brien, J. J., and Shriver, J. F.: The dynamics of the East Australian current system: the Tasman front, the east Auckland current and the East Cape current, J. Phys. Oceanogr., 31, 2917-2943, 2001.

van Aken, H. M., van Veldhoven, A. K., Veth, C., de Ruijter, W. P. M., van Leeuwen, P. J., Drijfhout, S. S., Whittle, C. P., and Rouault, M.: Observations of a young Agulhas ring, Astrid, during MARE in March 2000, Deep-Sea Res., 50, 167-195, 2003.

van Ballegooyen, R. C., Gründlingh, M. L., and Lutjeharms, J. R. E.: Eddy fluxes of heat and salt from the southwest Indian Ocean into the southeast Atlantic Ocean: A case study, J. Geophys. Res., 99, 14053-14070, 1994.

Weijer, W., de Ruijter, W. P. M., Dijkstra, H. A., and van Leeuwen, P. J.: Impact of interbasin exchange on the Atlantic Overturning Circulation., J. Phys. Oceanogr., 29, 2266-2284, 1999. 
Weijer, W., De Ruijter, W. P. M., and Dijkstra, H. A.: Stability of the Atlantic overturning circulation: Competition between Bering Strait freshwater flux and Agulhas heat and salt sources, J. Phys. Oceanogr., 31, 2385-2402, 2001.
Zharkov, V. and Nof, D.: Retroflection from slanted coastlines circumventing the "vorticity paradox", Ocean Sci. Discuss., 5, 1-37, 2008, http://www.ocean-sci-discuss.net/5/1/2008/. 